\title{
El amor pedagógico: miradas a su devenir en la pedagogía colombiana
}

\author{
Absalón Jiménez Becerra ${ }^{1}$ \\ Universidad Distrital Francisco José de Caldas, Colombia
}

Autor de correspondencia: ${ }^{1}$ abjimenezb@udistrital.edu.co Recibido: 27 de noviembre de 2020 Revisado: 5 de diciembre de 2020 Aprobado: 19 de junio de 2021 Publicado: 23 julio de 2021

\section{Resumen}

En los dos últimos siglos, la pedagogía moderna ha vivido cambios. Ya no es una propuesta de pedagogía ilustrada, como en inicios del siglo XIX, de carácter experiencial y experimental -objetiva y racional-. Hoy es una pedagogía subjetiva, simbólica, afectiva, comunicacional y emocional. El interés del presente artículo es hacer un recorrido por el amor pedagógico en Colombia, el cual nos permita revisar históricamente la vocación docente y asociarla con el amor pedagógico, a saber: el amor que el maestro debe sentir hacia los niños, el amor a la labor de enseñanza - acompañada de su equilibrio-, el amor al estudio y a lo que el maestro hace en la escuela y el amor al conocimiento. En la actualidad, el amor pedagógico hace parte de una relación de afecto emocional en la que el docente está inmerso de manera cotidiana. Se busca así una aproximación histórica y conceptual al tema para situarlo de manera reflexiva en la pedagogía colombiana.

Palabras clave: maestro, pedagogía, amor pedagógico, enseñanza, instrucción

\section{(c) $(1) \Theta \Theta$}

Para citar este artículo: Jiménez, A. (2021). El amor pedagógico: miradas a su devenir en la pedagogía colombiana. Praxis \& Saber, 12(30), e12123. https://doi.org/10.19053/22160159.v12. n30.2021.12123 


\title{
Pedagogical love: views on its occurrence in Colombian pedagogy
}

\begin{abstract}
In the last two centuries, modern pedagogy has undergone changes. It is no longer a proposal of enlightened pedagogy, as in the early 19th century, with an experiential and experimental nature-objective and rational. Today it is a subjective, symbolic, affective, communicational, and emotional pedagogy. For this article, the aim is to examine the pedagogical love in Colombia in order to review historically the teaching vocation and associate it with pedagogical love, which is: the love that the teacher should feel towards children, the love for the work of teaching-accompanied by its balance-the love for study and for what the teacher does at school, and the love for knowledge. Nowadays, pedagogical love is part of an emotional affective relationship in which the teacher is immersed daily. Thus, we seek a historical and conceptual approach to the subject in order to place it in a reflexive way in Colombian pedagogy.
\end{abstract}

Keywords: teacher, pedagogy, pedagogical love, teaching, instruction

\section{O amor pedagógico: visões sobre sua ocorrência na pedagogia colombiana}

\section{Resumo}

Nos últimos dois séculos, a pedagogia moderna tem experimentado mudanças. Não é mais uma proposta de pedagogia ilustrada, como no início do século XIX, de natureza experiencial e experimental - objetiva e racional. Hoje a pedagogia é subjetiva, simbólica, afetiva, comunicacional e emocional. Para este artigo, o objetivo é examinar o amor pedagógico na Colômbia a fim de rever historicamente a vocação pedagógica e associá-la ao amor pedagógico, que é: o amor que o professor deve sentir pelas crianças, o amor pelo trabalho de ensinar - acompanhado por seu equilíbrio - , o amor pelo estudo e pelo que o professor faz na escola e o amor pelo conhecimento. Atualmente, o amor pedagógico é parte de uma relação afetiva e emocional na qual o professor está imerso diariamente. Assim, busca-se uma abordagem histórica e conceitual do tema para situá-lo de forma reflexiva na pedagogia colombiana.

Palavras-chave: professor, pedagogia, amor pedagógico, ensino, instrução 
${ }^{1} \mathrm{Al}$ rastrear a los principales pedagogos en la modernidad, evidenciamos que el amor pedagógico ha transitado por varios caminos. Ha sido visto como parte consustancial de la vocación docente; como amor a la infancia; como un amor ilustrado; $y$, en un cuarto momento, como equilibrio y armonía en el proceso educativo. En el caso colombiano, el amor pedagógico está vinculado al amor a los niños, a la labor de enseñanza —acompañada de su equilibrio-, al estudio, a lo que el maestro hace en la escuela y al conocimiento, los cuales son temas trasversales en dicha preocupación. No obstante, en el mundo contemporáneo, el amor pedagógico hace parte de una relación de afecto emocional en la que el docente está inmerso de manera cotidiana. Así, queremos hacer una aproximación histórica y conceptual al tema en la modernidad para situarlo y reflexionarlo en la pedagogía colombiana ${ }^{2}$.

En la actualidad, desde la mirada de investigadores como Fayad (2010), las escuelas normales y las facultades de educación son un escenario institucional para la adquisición del don de la pedagogía que, como herramienta crítica, afecta no solo a la escuela, sino que compromete la institucionalidad formadora de maestros, la política pública de profesionalización docente y los procesos académicos y de resistencia vividos en nuestra historia educativa reciente. El maestro, al afirmar su don pedagógico como expresión de saber en su proceso formativo, por lo general, se fortalece en la asignatura que enseña, en su didáctica, en el currículo, en el aprendizaje y en la gestión escolar. Además, ese amor pedagógico que puede convertirse en un don adquirido es una preocupación transversal que puede afectar cómo se vive la escuela y los procesos educativos, de formación, de enseñanza y de aprendizaje. Está mediado por relaciones de significado, comunicacionales, simbólicas y subjetivas, que se conquistan en el proceso formativo.

De tal manera, para iniciar esta discusión, aclaramos que la pedagogía moderna —como el amor pedagógico- es una paradoja, en el sentido de que es constreñimiento; es garantizarle al otro - al niño, a la niña, al adolescente y al joven escolar - la conquista de autonomía y libertad en una etapa de su vida, mediada en un ambiente de disciplinamiento y vigilancia. Con estas ideas iniciales, buscamos hacer un balance del amor pedagógico en la modernidad, para reflexionar el tema en la pedagogía colombiana.

\section{Metodología}

Optamos por el método histórico en nuestras investigaciones, el cual es mitad arte y mitad ciencia social. La lógica de investigación en historia tiene como objeto inmediato el conocimiento histórico, el cual por naturaleza es: provisional e incompleto - no por ello falso-, selectivo - no por ello arbitrario- y definido por las preguntas del investigador (Jiménez, 2004). De tal manera, frente al tema del amor pedagógico, el cual ha sido poco

\footnotetext{
$1 \quad$ Este artículo es un producto de la investigación Pedagogía y formación docente en Colombia, financiada en 2019 por el Centro de Investigaciones y Desarrollo Científico (CIDC), de la Universidad Distrital Francisco José de Caldas de Bogotá.

2 Abordamos el amor pedagógico en la modernidad y en el mundo contemporáneo sin desconocer que amor y pedagogía - eros y paideia - fue un tema clave del pensamiento pedagógico griego. Platón en El banquete (1997) diferencia tres tipos de amor: el primero es el eros, visto como el deseo amoroso, la pasión y el anhelo de alcanzar aquello que se ama; luego la philía, que tiene un sentido de amor entre cercanos, un trato amoroso de afecto íntimo; y, en tercer lugar, el ágape, que es el amor general sin referencia al erotismo ni a la sexualidad (p. 26). De tal manera, el ágape es visto como un amor hacia la humanidad en general, el cual en la modernidad tomó un carácter filantrópico. El ágape es un amor total. En algunos casos en la pedagogía de la segunda mitad del siglo XIX, el amor pedagógico termina siendo un amor abnegado, dador, que ni demanda ni necesita ser correspondido. Es un amor desinteresado: dar sin esperar recibir nada a cambio.
} 
investigado en la historia de la educación colombiana, nos quedó como opción metodológica el inferir algunas ideas, es decir, iniciar una pesquisa con el fin de razonar hacia atrás.

Por ello, optamos de manera particular por el método indiciario, que no es inductivo ni deductivo; es abductivo. En este método se arranca por los hechos, sin tener al inicio ninguna teoría particular a la vista. De tal manera, cuando abordamos un tema novedoso - el amor pedagógico en Colombia - no encontramos una teoría pedagógica previa ni un estado del arte, sino que jugamos con el borramiento de la huella y con los paralelismos que podemos encontrar desde que surge la figura del maestro desde finales del siglo XVIII hasta la actualidad, acompañados de las respectivas reflexiones pedagógicas de época.

Como recientemente lo da a conocer Jiménez (2021) apoyado en Ginzburg, el historiador como un investigador social se debe mover en el indicio, en el asomo, en la sospecha y en la tentativa - asumida como sinónimo de tocar y de palpar las fuentes olvidadas en el pasado-. De tal manera, la historia como disciplina indiciaria es cualitativa y tiene por objeto casos, situaciones y documentos individuales, que se deben interpretar con ayuda de otras disciplinas. El método indiciario se basa en el análisis de las discordancias entre las preguntas del inquisidor y las respuestas de los inquiridos. Tiene en cuenta el proceso de contaminación, de deformación y de "borramiento" de las huellas dejadas por el pasado (Ginzburg, 2004). Así pues, con base en Ginzburg, el contexto hace parte del dominio de posibilidades históricamente determinadas. El historiador establece vínculos, relaciones y paralelismos, no siempre documentados en forma directa. Es decir, estos solo aparecen mientras hace referencia a fenómenos surgidos en un contexto común, en este caso de índole cultural, en relación con los profesores que han delimitado la pedagogía colombiana estos dos últimos siglos. La intención en esta investigación es movernos en el asomo y en la tentativa: es hilar las ideas de algunos filósofos, pedagogos y maestros, con el fin de establecer un corpus temático sobre el amor pedagógico en Colombia, como un tema importante de indagación.

\section{Una mirada al amor pedagógico desde la vocación docente}

En primer lugar, la idea del maestro sacerdote — que, además de evangelizar las almas y "amar al prójimo", también se encarga de la educación de la población- marcó el inicio de la formación de maestros en la modernidad. En el siglo XIX, en las escuelas normales, se demandó la vocación docente como elemento inherente de quien se entregaría a la profesión. En un inicio, el maestro moderno vivió ante todo de su valor moral frente a la comunidad, más que de su valor material. Para reafirmar su identidad, dependía no solo de su vocación, sino de su origen humilde y de su nobleza como ser humano, acompañada del carácter femenino de la profesión, de manera particular, de la mitificación a lo largo del siglo XX del papel de la mujer como educadora de primeras letras.

La vocación docente, como elemento consustancial de la pedagogía moderna, fue asociada también con el modelo tradicional de educación - a primera vista, el más lejano en el tiempo-. En Colombia, las congregaciones religiosas lideraron dicha propuesta. Se 
destacan los jesuitas ${ }^{3}$ y los lasallistas, ${ }^{4}$ en cuanto a sus primeras formulaciones y preceptos. Así, la idea de la vocación - junto con la concepción de que la educación es una especie de arte, un valor, una cosa que el maestro lleva dentro- es una de las premisas de un sistema educativo monopolizado por la Iglesia, la cual jugó un papel determinante hasta épocas recientes. La vocación docente desde la escuela tradicional fue vista como un valor, una inspiración, una inclinación o un interés para llevar un estilo de vida dedicado a la labor educativa, con base en un principio elemental: "el maestro nace, no se hace".

Al inicio de la época republicana, en 1822, por disposición de Francisco de Paula Santander, se creó la Escuela Normal Lancasteriana, encargada de la formación de maestros, que solo duraría un año. Esta escuela, además de las disposiciones iniciales de carácter público, civil y laico para la formación de maestros y la educación de los niños, estableció la necesidad de que el futuro maestro estudiara y dominara un método de enseñanza.

Luego, con la reforma de 1844, según Zuluaga (2018), se estableció una diferencia entre la escuela primaria y la escuela normal, pues esta última era una institución de saber formadora de maestros. La escuela normal desde un inicio había centrado su preocupación en torno al método de enseñanza que aplicaba el maestro en la escuela, que podría ser: individual, simultáneo o mutuo. En la reforma de 1844,

3 La Compañía de Jesús fue creada por Ignacio de Loyola. Fue reconocida por el Papa en 1540. Surgió de un grupo pequeño de hombres y en poco tiempo alcanzó una extensión e influencia extraordinaria en el campo educativo. De hecho, ha sido la organización más poderosa de la Iglesia para la educación de la población. Su influencia fue hegemónica hasta la segunda mitad del siglo XVIII. La Orden de los Jesuitas no fue creada con fines propiamente educativos, pues entre sus propósitos iniciales estaba la confesión, la predicación y la catequización. Sin embargo, una de las razones que los posicionó como educadores fue su presencia en el Nuevo Mundo. En América Latina hicieron presencia en todos los países y se enfrentaron con los reyes Borbones. Los jesuitas, por su carácter seglar, con estatutos y autoridades propias, son un grupo de curas diferentes. Tienen un carácter emprendedor y combativo. Viven en el siglo, en el mundo real y responden a sus necesidades (Luzuriaga, 1961, p. 123). En el caso colombiano, los primeros jesuitas llegaron a Cartagena de Indias en 1589, con el deseo de instalarse en la Nueva Granada. Luego, tuvieron fuerte presencia en Bogotá, en el centro del país. En los Llanos Orientales acompañaron el proceso de colonización. Fueron expulsados en tres ocasiones de nuestro territorio, en 1767, en 1850 y en 1861. Hasta finales del siglo XVIII en Colombia, la primera experiencia de lo que posteriormente sería la escuela pública, cuyo objetivo fundamental era la intervención de la población a través de la educación, fue labor de La Compañía de Jesús, que se encargó de educar a la población indígena y luego a los niños expósitos y pobres.

4 La Congregación de los Hermanos de las Escuelas Cristianas - o lasallistas - fue creada por el sacerdote, teólogo y pedagogo francés Juan Bautista de la Salle que consagró su vida a formar maestros laicos, destinados a la educación de los niños pobres. Desde 1680, cuando fundó en París las primeras escuelas de oficios dirigidas a jóvenes artesanos, la Congregación Lasallista estableció un sello propio en términos educativos. Los hermanos lasallistas tuvieron gran influencia en Colombia, en lo que respecta a la formación de maestros y en la administración de la escuela pública. Su labor pedagógica, realizada en 1863 en Ecuador, fue conocida por el entonces embajador de Colombia en ese país, Julián Trujillo, quien desde 1871 solicitó la presencia de esta comunidad en nuestro territorio, tarea apoyada por la prensa conservadora, como El Tradicionalista, de Miguel Antonio Caro, interesado en hacer conocer sus métodos de enseñanza para poner fin a la educación de los radicales. En Pasto se creó la primera comunidad de hermanos lasallistas en 1875, pero fueron expulsados un año más tarde, al estallar "la Guerra de las Escuelas", provocada por los estados de Antioquia y Tolima, con la participación de clérigos y obispos, por el enfrentamiento de los poderes civil y eclesial. En 1889 llegaron cinco monjes encargados de fundar la primera Comunidad de Escuelas Cristianas en Colombia, quienes se instalaron en Medellín y realizaron varias obras educativas de carácter gratuito. En 1893 llegaron a Bogotá y, en 1896, fundaron el Instituto La Salle, el noviciado de Chapinero y posteriormente la Escuela Normal Central y el Instituto Técnico Central. El ideal lasallista era lograr que en la escuela normal católica se desarrollaran tres principios fundamentales: espíritu cristiano, ciencia e investigación y servicio social. Por ello, los textos, los docentes, la práctica y los contenidos respondían a principios católicos. Además, inculcaban los doce valores del maestro: gravedad, silencio, humildad, prudencia, piedad, generosidad, sabiduría, paciencia, mesura, mansedumbre, celo y vigilancia. En 1905 - una vez superada la Guerra de los Mil Días-, la Escuela Normal Central en Bogotá reinició clases con treinta alumnos maestros becados. Se promulgó una enseñanza teórico-práctica, donde los alumnos observaban a los maestros y cómo se realizaban las clases y luego hacían lo propio. Este aprendizaje permitió desarrollar prácticas de antropometría y psicología experimental. La Misión Pedagógica Alemana -1924-1926- propuso establecer un sistema de control público a la educación y la creación de la Escuela Normal Nacional, por lo cual, la Escuela Normal Central fue cerrada y se impulsó la Normal de Tunja y el Instituto Pedagógico Nacional — hoy la UPN—. También, el Instituto Técnico Central fue anexado a la Facultad de Ingeniería de la Universidad Nacional en 1935. Años después, cuando Laureano Gómez estaba en el poder, en 1951, devolvió el Colegio a Los Hermanos Lasallistas. Desde entonces, el Instituto Técnico Central ha continuado su obra de formación técnica (Carvajal \& Mesa, 1990). 
el maestro formado en la escuela normal debía tener la capacidad de dirigir una escuela como su conocimiento acerca de las materias de enseñanza y del método. Los requisitos para ser admitido como alumno en la Escuela Normal eran los siguientes: tener entre 18 y 45 años, poseer buena conducta moral y religiosa, no padecer enfermedad contagiosa, leer y escribir, aunque fuera medianamente, saber la Doctrina cristiana y no haber sido sancionado penalmente. (Zuluaga, 2018, p. 339)

Desde la reforma de 1844, se reflexionó sobre la práctica pedagógica, la comunicación entre los maestros y la profundización de conocimientos, acompañadas de un cuestionamiento a los métodos de enseñanza individual y mutuo. El método individual se había declarado en desuso por su imposibilidad en términos prácticos. El método mutuo -o lancasterianotambién fue cuestionado, debido a que no pudo ser aplicado en su totalidad en la escuela colombiana. Así, se reivindicó la propuesta pestalozziana en lo que respecta al método simultáneo para la enseñanza de la gramática y la matemática, entre otros. En el método establecido por Pestalozzi, el maestro recuperó el papel central en el proceso de enseñanza y se reivindicó la intuición del niño como elemento fundamental para el desarrollo de su inteligencia.

Las primeras escuelas normales pestalozzianas, desde 1870, como garantes de la moral, se basaron en dos principios básicos: "donde termina la labor de la iglesia inicia la labor de la escuela" y "donde termina la labor del cura inicia la labor de maestros". Desde entonces, el maestro normalista fue garante de la moral cristiana, acompañado de la vocación hacia la labor de enseñanza. Se reconoció que la pedagogía es un talento adquirido que se debe terminar de estudiar y de pulir. Así, la vocación docente, desde el siglo XIX, como figuración ${ }^{5}$, es un elemento condicionante e importante para que en el mundo contemporáneo retomemos el tema del amor a lo que el maestro hace en la escuela, el amor pedagógico.

\section{El amor pedagógico en la pedagogía moderna}

Nuestra conjetura en este trabajo es que la vocación docente de inicios del siglo XIX se convierte en amor pedagógico - visto como un amor hacia lo que el maestro hace en la escuela-, un amor ya sea hacia la formación del sujeto, hacia la educación de este o hacia las prácticas de enseñanza. En la actualidad, el amor pedagógico está fuertemente afectado por lo emocional y lo afectivo - por cómo se siente el maestro frente a sus responsabilidades-, pero, ante todo, sin perder de vista que el maestro es un sujeto en una experiencia institucional - la escuela - y comunitaria — con los estudiantes, demás profesores y padres de familia-. Ese amor pedagógico como heredero de la vocación docente, al igual que la pedagogía moderna, es una rareza insertada en la relación de saber y poder entre el mundo adulto y el mundo infantil, entre quien enseña y otro que aprende, entre quien educa y quien es educado. A continuación, abordaremos algunas expresiones de amor pedagógico en el marco del inicio de la pedagogía moderna, al tener en cuenta la postura de tres pedagogos que establecieron su base epistemológica.

5 La figuración es un entramado de interdependencia, de equilibrios de poder más o menos inestables. La reconfiguración de la escuela es producida por la presión específica que ejercen las figuras sociales, constituida por las personas en interacción sobre esas mismas personas. Los entramados configurados por los hombres - las figuraciones sociales- sufren transformaciones que requieren a mediano y largo plazo una reorganización de la percepción y del pensamiento expresado por medio del lenguaje (Elias, 1975, p. 17). 


\section{El amor pedagógico como amor a la infancia}

Rousseau, en Emilio o de la educación (2004) —dado a conocer en 1762-, estableció las bases de la pedagogía moderna al descubrir la infancia, de manera explícita y objetiva. El buen ayo -o preceptor- debía amar al niño, amar los juegos infantiles y valorar sus experiencias vitales, el desarrollo de sus sensaciones y de sus percepciones y su imaginación. En algún momento, el ayo debía acercar al niño a la lectura, a la cultura y a la conquista del conocimiento:

Hombres, sed humanos que es vuestra obligación primera, sedlo con todos los estados, con todas las edades, con todo cuanto es propio del hombre. ¡Qué saber tendréis fuera de la humanidad? Amad la infancia; favoreced sus juegos, sus deleites, su amable instinto. (Rousseau, 2004, p. 47)

Desde su perspectiva, en el proceso educativo moderno, la infancia, como parte de la experiencia vital del sujeto, debía ser valorada de manera positiva por parte del mundo adulto. De tal manera:

la humanidad tiene su lugar en el orden de las cosas y el niño el suyo en el orden de la vida humana; es necesario considerar al hombre en el hombre y al niño en el niño. Todo cuanto por su bien podamos hacer es señalar a cada uno su lugar, colocarle en él y coordinar las pasiones humanas según la constitución del hombre: lo demás pende de causas extrañas que no están en nuestras manos. (Rousseau, 2004, p. 48)

Con Rousseau debemos valorar las trasformaciones cualitativas que vive este sujeto, pues Emilio pasa de la infancia a la adolescencia y luego a la juventud. Su proceso educativo llega hasta los veinticinco años, cuando conoce a Sofía. Corren una carrera y se casa con ella. Con este filósofo, el iusnaturalismo se personificó en el proceso educativo de Emilio. De tal manera, el niño conquista conocimiento en la interacción con la naturaleza y luego con las personas y las cosas.

Así, la labor del ayo es, en esencia, educar a Emilio en términos morales, para formar de esta manera un buen ciudadano, un individuo universal que valore la cultura y que conquiste el uso de razón como expresión de mayoría de edad ilustrada. Desde la perspectiva filosófica de Rousseau, "el hombre nace bueno y la sociedad lo corrompe". El niño, en general, es visto como el buen salvaje. El niño, en oposición a lo que planteaba la Iglesia católica en aquella época, es bueno, inocente y frágil, y al mundo adulto le corresponde asistirlo y cuidarlo.

El primer profesor y amigo del niño debe ser su padre, pero, en algún momento, la familia confiará el proceso educativo del niño a un experto, el ayo. La bondad del niño, su inocencia y su cuidado desde entonces fueron una responsabilidad del adulto, ante cuando había fallas en las prácticas de asistencia y cuidado hacia el niño. El buen ayo es aquel que, además de amar al niño, lo asiste, lo cuida y lo educa.

\section{El amor pedagógico como un amor ilustrado}

Para Pestalozzi, la escuela era el complemento de la educación doméstica. Tenía como fin prepararnos para afrontar la vida. En esta institución, el amor de la madre es remplazado por el amor ilustrado, el cual no es más que la razón cultivada y refinada. El medio más puro y esencial para avivar la capacidad común de la naturaleza humana solo procedía 
originariamente del amor acompañado del trabajo pedagógico del maestro. Así, el amor como medio educativo era parte esencial de su propuesta que tomaba cuerpo en la pedagogía objetiva. En su libro El canto del cisne (1996), Pestalozzi aclara:

Esta será un sueño, un medio de alucinación del pueblo si no se hace salir del único e insubstituible fundamento de la educación naturalmente adecuada para lo humano, el amor, las creencias y su permanente compañera la capacidad de acción. (p. 75)

La pedagogía objetiva buscaba una formación integral que formara en el estudiante el corazón, la cabeza y la mano. Así, la educación elemental consistía en la educación de la humanidad, mediada por una relación de afecto como herramienta educativa. De sus postulados se desprende una concepción tripartita del sujeto, acompañada de acciones educativas: lo físico, lo intelectual y lo moral en una interacción continua con el medio.

Como educador, Pestalozzi se caracterizó por su humildad y abnegación. Se entregó de manera integral en su labor pedagógica a los niños. En su tumba reza uno de sus principios de vida: "Todo para los demás, nada para sí". Como discípulo de Kant y de Rousseau, reivindicó el amor pedagógico como amor ilustrado, que es sinónimo de la razón refinada y cultivada, garantizada por el proceso educativo sacado adelante por el maestro en la escuela.

\section{El amor pedagógico como armonía y equilibrio en el proceso educativo}

En la actividad educativa, Herbart (1914) diferencia tres momentos esenciales: el gobierno, la instrucción y la disciplina. El gobierno se dirige a la conservación del orden, a la conducta externa de los niños, para lo cual el medio más importante es mantenerlos activos. El amor es el medio pedagógico para mantener el orden y descansa sobre la armonía de los sentimientos y la costumbre. De acuerdo con sus observaciones y su experiencia, se evidenciaba así lo difícil que era para el maestro conquistar al niño. Desde su perspectiva, el amor pedagógico no lo adquiere quien se mantiene aislado, habla siempre en tono elevado y adopta en su manera un aire mezquinamente calculado. Tampoco lo gana quien se hace un ser vulgar ni quien, debiendo ser agradable, pero al mismo tiempo reflexivo, busca su propio placer al participar en el de los niños.

La armonía de los sentimientos que el amor exige puede producirse de dos modos: o bien penetrando el educador en los sentimientos del alumno y uniéndose a ellos con delicadeza, sin hablar de ello, o bien cuidando de hacerse el mismo, en cierto modo asequible a la simpatía de su discípulo; esto es difícil, pero debe combinarse, sin embargo, con aquello, porque el discípulo solo puede poner energía propia en esta relación cuando tiene de algún modo una cosa en común con el educador. Pero el amor del niño es pasajero y efímero, si no va acompañado suficientemente de la costumbre. El tiempo, los cuidados amorosos, las relaciones íntimas todo ello da solidez entre el educador y el niño. (Herbart, 1914, p. 82)

En relación con el gobierno de los niños, aclara que una educación que no se ocupe del desorden de los niños demostraría su desconocimiento hacia ellos. Si en las prácticas educativas en la familia, por lo general, el amor es garantizado por la madre y el principio de autoridad, por el padre, al profesor le correspondería desarrollar las prácticas de instrucción, sin desconocer el peso del amor y de la disciplina en el proceso educativo. De tal manera, cuando hace referencia al gobierno de los niños, se establece un dispositivo de alianza entre los padres de familia y el profesor. En palabras de Herbart (1914): 
No es posible, además, dar ni una hora de clase sin empuñar con mano firme, pero suave, las riendas del gobierno. $\mathrm{Si}$, por último, se quiere repartir exactamente entre el educador propiamente dicho y los padres todo lo que le corresponde a la crianza de los niños, es preciso esforzarse en disponer convenientemente entre ambas partes la relación en que se hallan por la ayuda recíproca que se prestan. (p. 76)

La disciplina al buscar el mismo objetivo que la educación como lo es la formación del sujeto se apoya en la relación directa y en el trato personal, pero al dirigirse más al comportamiento externo puede dejar por fuera la formación moral. Así, diferenciar las buenas de las malas acciones se constituye en un objetivo de la educación moderna, del gobierno de los niños, que incluye el buen trato hacia ellos. Por otro lado, la instrucción tiene por fin, como toda educación, la virtud $-\mathrm{o}$ la formación de la fuerza de carácter moral-. Así, al profesor, en búsqueda del equilibrio educativo, le correspondería desarrollar las prácticas de instrucción, sin desconocer el peso del amor y de la disciplina, con el fin de formar un hombre ilustrado y educado.

\section{El amor pedagógico en Colombia}

Para hablar de amor pedagógico en Colombia, debemos remontarnos a una de las primeras proclamas educativas de los criollos en un ambiente caldeado de ideas de cambio revolucionarias. Nos referimos a la proclama de Francisco José de Caldas realizada en 1808, en el Semanario del Nuevo Reino de Granada, que llevó por título Plan para las escuelas patrióticas, firmado con el seudónimo de "El amigo de los niños". En este documento, de manera inicial, aclara:

Sean las formas de gobierno las que fueren, y denomínense monárquicos, democráticos, aristocráticos o despóticos, en todos es necesario que tengan los jóvenes de ambos sexos para el logro de los fines que se proponen los gobiernos, una educación pública, gratuita, igual [uniforme], sabia y sostenida. En ella está el origen de casi todos los bienes, así como en la defectuosa o nula, todos los males. (Caldas, 1941, p. 67)

Este control de la formación moral de los niños y jóvenes, que para estos ilustrados resultaba de una complementariedad pacífica - y no dogmática - entre la Iglesia y el Estado, se volvió una de las fuentes del conflicto que ha marcado la construcción de esa promesa de lo público en el sistema educativo republicano.

También, desde entonces, el maestro es la piedra angular del sistema. "El amigo de los niños" pide para el maestro, además de los consabidos requisitos de buenas costumbres y conocimientos, lo siguiente:

Yo quisiera además que se indagase mucho sobre la sensibilidad de su corazón, esto es sobre si ama a los niños, si es compasivo con los miserables y si tiene el discernimiento suficiente para saber que, siendo natural a los niños la inclinación al juego y a la frivolidad, sepa también cómo ha de graduar sus faltas, para que, según el género de su malicia, aplique el género de corrección más conforme. En una palabra, debe ser un verdadero filósofo que conozca el corazón humano, el estado de nuestra naturaleza, y aquel en que se hallan los niños, tan fácil a imprimírseles lo bueno como lo malo, y de este modo sabrá también que los ejemplos prácticos enseñan más que los preceptos. (Caldas, 1941, p. 83) 
Como lo aclaró Saldarriaga (2003), este amor pedagógico no es religioso: es filantrópico, laico y valoriza la figura del maestro en un momento en que aún no habían hecho su aparición las escuelas normales. Pero hay aún otra promesa en el plan patriótico: su visión filosófica del amor pedagógico le llevó a criticar "los métodos comunes que se han seguido hasta aquí en nuestras escuelas, tanto de Europa como de América" (Caldas, 1941, p. 78), sobre todo uno que

ha sido inspirarles a los niños en las escuelas y aun en los colegios, el espíritu de ambición a los puestos elevados y preeminentes, a las distinciones de clase con su nomenclatura de emperadores, cónsules, capitanes ${ }^{6}$, y a la superioridad de unos sobre los otros, ideas que se amalgaman tan bien con la inclinación del corazón humano, que suelen conservarse después en los jóvenes por todo el resto de la vida... Debe desterrarse de nuestras escuelas toda práctica que pueda introducir en el corazón de los niños la semilla de la ambición, porque sería fomentar en ellos el orgullo, que es el patrimonio que heredamos de nuestros padres. Allí solo debe inspirárseles amor recíproco. (pp. 78-79)

Más aún, el Semanario combate otra verdad común entonces entre maestros y padres de familia: la necesidad de castigos físicos, la humillación o las amenazas verbales "con que se quiere corregir las pueriles faltas de unos niños de seis a ocho años" (p. 83). En este punto, es necesario citar su propuesta rousseauniana sobre la posición del maestro: proponía que se reformasen también

los nombres usuales de maestro, preceptor o docto, con los que suelen denominarse, porque estos a mi entender encierran una significación algo fastuosa, poco modesta, y que no puede inspirar en los niños aquella confianza con la cual conviene en su edad que traten a sus directores, para que estos también conozcan la condición y carácter de sus alumnos. Los de director, padre de la patria, amigo de los niños, o algún nombre griego que alcance el sentido de estos, son más propios que los otros. (Caldas, 1941, p. 85)

Tal vez, esa palabra griega que les faltaba era ipedagogo! Sin embargo, hubo que esperar muchos años de república para que maestras y maestros fueran vistos de tal forma. Lo fundamental de esta primera proclama de la pedagogía colombiana es que, a la luz de la aparición de la escuela pública, se delimitó por primera vez el maestro moderno, el maestro de la república que - como amigo de los niños- debía garantizar cierto tipo de amor ilustrado de carácter laico, que sirviera de intermediario para consolidar el escenario de lo público.

Luego de ocho décadas, el primer pedagogo moderno del país fue Martín Restrepo Mejía, quien, con su hermano Luis, en 1888 escribió el libro Elementos de pedagogía (1911), el principal manual - por lo menos hasta 1920 - para la formación de maestros en las escuelas normales de Colombia y Ecuador. En dicho texto, en términos de práctica pedagógica, se materializó la positivización del niño en el discurso pedagógico colombiano, como respuesta a la reforma educativa de 1870 y al proceso de psicologización y pedagogización del niño. Con Restrepo evidenciamos el amor pedagógico de manera inicial, como un amor a la labor de enseñanza o, más bien, un amor equilibrado entre las prácticas de disciplinamiento, educativas y de instrucción.

6 Alusión crítica al sistema de "emulación” utilizado en los colegios jesuitas. 
El niño de la pedagogía moderna, -de la pedagogía racional-, debía pensarse no sólo con bases científicas en cuanto el avance del peso de la intuición como de la psicología que comenzaba a consolidarse en disciplina moderna, acompañada de los principios de proporcionalidad en las tareas y el grado desarrollo de los sujetos, sino en elementos de carácter indulgente y amoroso.

En el manual Elementos de la pedagogía (Restrepo \& Restrepo, 1911), se enseñaba a tomar distancia de los métodos de castigo del sistema lancasteriano - "la letra con sangre entra" $y$ "la labor con dolor" - , pero los reemplazaba por los "avances" de una disciplina del honor o la emulación, un sistema rigurosamente escalonado, orientado hacia la formación del autogobierno - entendido como "amor al deber" -, lo cual hacía pasar al niño:

de un "estímulo material" en esa primera edad donde el niño solo aprecia los objetos tangibles, luego pasar a la emulación por ganar el afecto de sus compañeros y superiores (palabras de aprobación y estímulo), en una edad mayor fomentar la emulación por el honor y llegar por fin a la verdadera, la noble emulación por amor al bien y al sentimiento íntimo del deber cumplido. (Restrepo \& Restrepo, 1911, p. 188)

La disciplina era vista por Restrepo (1912) como el medio por el cual se valían los padres y el maestro para que la voluntad del niño se acostumbrara al orden:

Los medios de que se valía la disciplina para obtener dicho fin eran tres: la ley, la regla u orden, que prescribía la vida del niño; la autoridad, con que se imponían estas órdenes; y los estímulos, con que se excitan la voluntad del niño. Los medios debían emplearse de modo tal que tendiera a que el niño se acomodase gustoso y convencido a las condiciones de la orden a fin de que poco a poco fueran innecesarios tanto la autoridad paterna y los estímulos y fuera capaz de gobernarse así mismo, por convicción y voluntad recta. La disciplina que de esta manera y con este propósito procedía era la que se llamaba educativa. (p. 88)

De tal manera, la pedagogía colombiana desde entonces establece la diferencia entre la disciplina social y la disciplina educativa. La primera externa al sujeto se interesaba por el orden y la conducta del grupo, la segunda se preocupa por la perfección moral del individuo. En la escuela, el maestro se vio obligado a buscar un equilibro entre la disciplina social y la disciplina educativa bajo un principio de autoridad y afecto que debía formar a un nuevo sujeto racional y tolerante.

Esta experiencia de amor pedagógico, en la pedagogía clásica, consistía en establecer una red paternal y pastoral que se expresaba en una tecnología moral sofisticada. El ideal de este nuevo tipo de disciplina era poner en juego un mecanismo de presencias y ausencias del maestro a través de su voz o de su silencio, de su mirada o su indiferencia, para identificar o quitar la identificación afectiva que el maestro depositaba en el niño. En el límite, el peor castigo llegaba a ser el dolor moral del niño por efecto de que "¡el maestro ya no me mira!" (Saldarriaga, 2003, p. 164).

En cuanto a la autoridad, Restrepo, en otro de sus libros, Pedagogía doméstica (1912), aclaraba que los padres debían ejercer su autoridad con firmeza y dulzura. Bastaba la firmeza para la autoridad social, pero, en el hogar donde la autoridad era educadora, se debía mezclar con el corazón y la cordialidad de los padres:

Lo que importaba en la educación moral es el amor a la ley que se obedecía, porque de este 
modo se ponía al niño en el camino de saber y querer gobernarse a sí mismo que era el punto en que la educación se daba por terminada. El gobierno, el self government que dicen los ingleses, es el fin de la educación moral. (Restrepo, 1912, p. 191)

Restrepo, como intelectual de la educación y precursor católico de la escuela nueva, representa una transición de carácter modernizante entre una pedagogía cristiana - que, en términos filantrópicos, demandó el amor hacia la labor de enseñanza, que era la labor propia del maestro- y la pedagogía moderna, la pedagogía de la objetivación, que establecía otros fines ontológicos y políticos para transformar al sujeto, la escuela y la sociedad a lo largo del siglo XX. En sus posturas académicas y de pensamiento, este amor pedagógico transita de la labor de enseñanza del maestro al amor hacia el niño, acompañado de un equilibrio en términos de lo que era su labor educativa y de disciplinamiento. En el fondo, el amor pedagógico, mediante prácticas de enseñanza y educativas, buscaba la perfección moral del individuo.

Luego, en la primera mitad del siglo XX, Agustín Nieto Caballero, como gestor de la Escuela Activa en Colombia, tomó posición frente al amor pedagógico al reflexionar constantemente en torno al tema del maestro, su relación con la disciplina y el principio de autoridad que este ejerce. La disciplina de la confianza fue una alternativa al castigo físico e infamante, reconocido por la escuela tradicional como parte de la práctica educativa en torno al niño. También fue una alternativa frente a la emulación que promovían las congregaciones religiosas, particularmente los hermanos cristianos y los jesuitas. Era una posibilidad formativa que reemplazaba la aflicción física hacia el estudiante.

Para Nieto (1966), el dolor y la humillación del niño, como parte de la norma educativa de la primera mitad del siglo XX, agotaba, envejecía, deprimía, aniquilaba, mataba toda ilusión y ensombrecía el espíritu de la persona. La disciplina de la confianza fue una nueva manera de entender las relaciones entre el maestro y el estudiante en el marco de la escuela activa, mediante la cual se hacía una honda labor en las conciencias de ambos sujetos. Desde su particular perspectiva liberal, la sanción ruda y muchas veces cruel de la escuela vieja formó a menudo a hombres faltos de franqueza, así como a un tipo de hombre que no aprendió a mirar de frente; a un hombre doble, que terminaba siendo servil o tirano.

Desde la disciplina de la confianza, la educación del niño y del joven requería atención del maestro en todos los momentos. Las pequeñas faltas, si eran de una misma índole, iban formando un hábito, y este sería siempre el eje de la personalidad. Desde su mirada, el buen hábito economizaba energías a todo instante; el mal hábito las destruía persistentemente. Así, el hábito podía tanto liberar el espíritu del cuerpo como hacerlo su esclavo. La fuerza de los hábitos adquiridos estaba en que, una vez se arraigaban, pertenecían al orden biológico. La disciplina de la confianza buscaba formar estudiantes con criterio, reflexivos y con una personalidad definida.

El maestro que promovía la disciplina de la confianza, para conservar su autoridad, debía tener en su mente una lista de jamases para no olvidar nunca:

- Jamás ser injusto.

- Jamás obrar con ira.

- Jamás usar amenazas. 
- Jamás rechazar los reclamos que puedan hacerle.

- Jamás ofender al alumno.

- Jamás humillarlo.

- Jamás dejar de dar buen ejemplo en obras y palabras.

- Jamás olvidar los objetivos vitales que han de moverlo.

- Jamás rehuir el frecuente examen de conciencia sobre su conducta.

Para Nieto (1966), no existía programa más importante en la escuela moderna que la selección de los maestros. De acuerdo con sus reflexiones, aspectos fundamentales como programas, métodos, disciplina, instrucción y educación, todo sería bueno o malo, según fuera el maestro. El maestro, como eje central de la escuela, debe encarnar el amor al estudio, la laboriosidad, la modestia efectiva, el tacto, la suavidad y, a la vez, la firmeza de carácter. En este sentido, el amor pedagógico se materializa en la siguiente reflexión:

El que no tenga contento el corazón, que no se haga educador... Lo cierto es que quien se dedica a esta tarea ha de ser siempre joven, joven de espíritu al menos, para que en él sea un impulso el amor a lo que hace, la consagración absoluta a la obra que se entrega. Su primera cualidad, el entusiasmo contagioso y alentador. Más esto, con ser mucho no lo será todo. El maestro ha de tener inteligencia para comprender y desarrollar un programa; ha de conocer los métodos para no andar a tientas, $\mathrm{y}$ ha de poseer cierta experiencia y las buenas maneras y los buenos hábitos de orden, de puntualidad, de pulcritud, que puedan ser imitados por los alumnos. Un sereno espíritu de justicia tendrá que guiar todos sus actos; un perfecto dominio de su temperamento debe impedir el que su conducta deje de ser una vez siquiera, caballerosa y digna. (Nieto, 1966, p. 83)

Para el maestro moderno, las relaciones de cordialidad que se vivían en la escuela activa con el niño no debían poner en cuestión el principio de autoridad, el cual simplemente debía ser la conciencia de una mayor responsabilidad. El maestro debía saber que la autoridad exigía deberes antes que derechos, a la vez que normas de pulcritud, de justicia y de verdad. El maestro no podía perder su posición jerárquica en la escuela: debía ser un sujeto sobrio en prédicas, pero elocuente en laboriosidad.

El amor pedagógico de Nieto (1966) no se podía pensar de manera independiente al principio de autoridad académica que ejerce el maestro en la escuela. El amor pedagógico del maestro se encarnaba en el amor al estudio, en el tacto, en la firmeza, en los buenos hábitos y en la atención que ponía a sus alumnos. El amor pedagógico, como sinónimo de las buenas maneras y de hábitos de una persona laboriosa - una persona espiritualmente joven-, tampoco se podía pensar de manera independiente al principio de la disciplina de la confianza, mediante la cual se buscaba formar a un sujeto autónomo, moderno y racional. El amor pedagógico se basaba en un principio de constreñimiento - en una paradoja-, como lo es: "amar educando" y "generar autonomía disciplinando" a las nuevas generaciones.

Por último, en la década de los 80 del siglo XX, el maestro Estanislao Zuleta retomó el tema del amor pedagógico. Para poder ser un buen maestro, según sus planteamientos, era necesario amar lo que se enseña. Para poder introducir algo en el estudiante, era necesario estar convencido de ello y amarlo. No habría transmisión posible que el profesor pudiera 
hacer de una pasión que él no tuviera por el tema. En una de sus conocidas entrevistas, aclaraba:

La educación no puede eludir esta exigencia sin la cual su ineficacia es máxima: el amor hacia aquello que se está tratando de enseñar. Además, ese amor solo puede dar quien lo tiene, y en últimas eso es lo que se trasmite. Nadie puede enseñar lo que no ama, aunque se sepa todos los manuales del mundo, porque lo que comunica a los estudiantes no es tanto lo que dicen los manuales, como el aburrimiento que a él mismo le causan. (Suárez, 1985, como se citó en Suárez \& Valencia, 1995, p. 61)

En otra de sus reflexiones, proponía una educación filosófica, al entender por filosofía: el amor que el sujeto establece con el conocimiento. Frente a este escenario, su propuesta educativa se mueve en un frente de trabajo filosófico, eminentemente kantiano. Así reivindicó, en sus diversas intervenciones, al sujeto de la razón, la conquista de su autonomía y la mayoría de edad. Desde tal perspectiva, se debe entender por filosofía: la posibilidad de pensar las cosas, de hacer preguntas y de ver contradicciones:

Asumo el concepto de filosofía en un sentido muy amplio, en el sentido griego de amor a la sabiduría. Es un filósofo el hombre que quiere saber; el hombre que aspira a que el saber sea la realización de su ser; el hombre que quiere saber por qué hace algo, para qué lo hace, para quién lo hace; el hombre que tiene una exigencia de autonomía. (Suárez, 1985, como se citó en Suárez \& Valencia, 1995, p. 25)

Para Zuleta (1975), estudiar a los niños demanda un abordaje crítico de las diferentes ideologías que reinan sobre ellos, a través de las cuales se piensan, se sienten, se viven e incluso se utilizan. Los niños, desde épocas recientes, fueron objeto de amor. Sin embargo, la manera de amar a los niños está articulada con cómo los piensan los adultos. Desde el moralismo moderno, se reivindica el amor a los niños como una manera de culpabilizar al adulto. En este sentido, según la antigua tradición, los niños se estiman como "inocentes" y los adultos como "culpables", perturbadores de la espontaneidad y de la inocencia infantil. Desde esta perspectiva:

Los niños son un producto de la sociedad y, por lo tanto, el estudio de estos es una investigación que tiene que pasar a investigar la conducta de la sociedad con relación a los niños. Volvamos un momento al tema de la oposición entre espontaneidad y coacción. Esta oposición que se ha difundido mucho y ha inspirado tan diferentes tipos de pedagogía, supone que las imposiciones son una mala cosa, y que la imposición, prohibición y coacción es algo que debe ser en sí mismo considerado como malo, precisamente, porque cree que el desarrollo infantil es una maduración espontánea, pero ya esa primera suposición es ideología... El desarrollo infantil es un ingreso muy dramático en una cultura existente. Por su puesto, que no hay ningún desarrollo espontáneo de ningún lenguaje, por ejemplo, el lenguaje es evidentemente una magnífica imposición. Es una imposición de normas: las normas lingüísticas. (Zuleta, 1975, p. 7)

El niño, desde la antigüedad, quedó situado como quien se ubica y apunta hacia el mundo adulto. La "inocencia" se asume como un mito primitivo del origen de cada ser individual, y la imagen de escándalo que liquida la inocencia como el pecado principal. Rousseau (2004) se basa en el mito del pecado original: el niño viene de un estado de salvajismo, "el buen salvaje", un hombre primitivo y primitivamente bueno. Para Zuleta (1975), Rousseau cuenta 
que una de las cosas que más puede perturbar la educación del niño es que llegue a conocer algunas necesidades o deseos de los adultos que todavía no le corresponden a su edad. El ingreso a la sociedad está lleno de coacciones y prohibiciones. La socialización de la persona es en gran parte la interiorización de prohibiciones.

El amor pedagógico inmerso en esa relación de tensión se encarna en el amor hacia lo que se enseña. Desde su perspectiva, el maestro debe amar el conocimiento. De hecho, en otro de sus ensayos (Zuleta, 1974), nos aclaró que leer es trabajar, es apropiarse de un autor y un tema para dialogar con él, para establecer una relación dialéctica con el conocimiento. El amor pedagógico no es fácil; se materializa en un ambiente de tensión entre el mundo adulto y el mundo infantil, entre la falta de habilidad para educar y la inocencia del niño, entre la guía que puede realizar el profesor y el espíritu investigativo del estudiante. El amor pedagógico enfrenta al maestro a un escenario platónico en el que a primera vista todo es perfecto, pero que en el fondo lo enfrenta al amor al conocimiento, al compromiso frente a la enseñanza y a una relación de tensión con el mundo infantil.

Finalmente, Saldarriaga (2006), tal vez sin proponérselo, se ubica en una posición muy cercana a la establecida por Zuleta cuando define el amor pedagógico como "un dispositivo destinado a aunar las relaciones entre amor y conocimiento, haciéndolas pasar por la enseñanza" (p. 46). No obstante, desde su particular perspectiva genealógica, la pedagogía es un dispositivo de poder pastoral, el cual emergió del ámbito religioso para hacer puente con las formas secularizadas del pastorado moderno. En el mundo contemporáneo, dichas prácticas de pastorado han llevado a la pedagogización de las relaciones políticas y sociales, que se convierten en un síntoma de la trasformación de la pedagogía en una nueva forma de poder mediada por el peso de las ciencias del lenguaje, la comunicación y la información.

En Colombia, pedagogos como Antanas Mockus nos han trasladado a ese escenario en el que comenzamos a valorar de manera positiva a cierto tipo de pedagogía subjetiva, reconstructiva y cargada de simbolismo, lo que llevó, en los años 90, a la pedagogización y escolarización de la ciudad (Jiménez, 2018, p. 228). En este contexto, las pedagogías invisibles y hedonistas disminuyeron las relaciones de jerarquización que predominaron en la pedagogía tradicional y, por consiguiente, el docente en la actualidad establece con la población una relación cercana en la que predomina una actitud social, intersubjetiva y de cooperación.

En el mundo contemporáneo, el buen pedagogo es aquel que tiene la capacidad de comunicar de manera exitosa lo que sabe; que no rompe la comunicación; que hace entender su conocimiento; que, mientras forma, establece una relación exitosa con la población en términos educativos. La rehumanización de la pedagogía -el amor pedagógico contemporáneo- ha conllevado resolver las prácticas educativas y de formación de la población en el escenario comunicacional, el cual puede ser falible y reconstructivo.

\section{Conclusiones}

El amor pedagógico se convierte en la pedagogía moderna como parte de una herencia de la vocación docente, en el marco de lo que fue la escuela tradicional y la impronta que en ella dejaron las congregaciones religiosas en América Latina y particularmente en Colombia, entre otras, la de los jesuitas y los lasallistas. Los miembros de estas congregaciones, además 
de educadores, se preocuparon históricamente por la formación docente con cierto nivel de compromiso y de entrega en el que se reivindicó la vocación como expresión de amor pedagógico, sumada a otra serie de valores, como el origen humilde de los maestros, su nobleza y el carácter femenino de la profesión.

No obstante, cuando nacieron las escuelas normales, apareció un cuestionamiento en torno a la vocación docente, lo que llevó a reflexionar si en realidad el maestro nace con esa vocación o, más bien, se hace ya sea en el proceso formativo o en la práctica pedagógica institucional. De hecho, cuando aparecen las primeras escuelas normales en el siglo XIX y luego las facultades de educación en el siglo XX, se evidencia que la pedagogía es un talento que el maestro debe estudiar, conquistar y pulir en el proceso formativo y en el desarrollo de su práctica pedagógica. Dicha vocación docente puede ser un don pedagógico que, como herramienta crítica — de acuerdo con la mirada de Fayad (2010) —, afecta no solo a la escuela, sino que a la vez compromete a la institucionalidad formadora de maestros, la política pública de profesionalización docente y los procesos académicos y de resistencia vividos en nuestra historia educativa reciente. La misma institución escolar es una condición de posibilidad para la conquista del amor pedagógico, expresado en un don adquirido que, como espacio de resistencia, genera en el maestro un nivel de conocimiento en temas relacionados con la enseñanza, el aprendizaje, la formación, el currículo y la gestión escolar, que lo diferencia frente a otros profesionales.

En la modernidad, el amor pedagógico, en términos ontológicos, se expresó en tres niveles de preocupación: el amor a la infancia; un amor ilustrado y racional que el maestro garantiza a los niños; y el amor como parte de un equilibrio en el proceso educativo, que concierne a la disciplina y a la enseñanza.

En general, la pedagogía moderna, al igual que el amor pedagógico, es una paradoja en la que se debe garantizar la conquista de autonomía y la libertad del sujeto en una etapa de su vida, intervenida por el control institucional establecido por el mundo adulto. También, esta paradoja se expresa por medio de una relación de saber y poder en torno al mismo sujeto que contiene el discurso pedagógico moderno y contemporáneo, que se muestra como sutil, capilar e inmanente en las prácticas pedagógicas de los maestros.

De tal manera, en el pensamiento pedagógico colombiano (Jiménez, 2018), el amor pedagógico no ha sido un enunciado totalmente descuidado de nuestras prácticas, como lo creíamos a primera vista. Así, el amor a los niños aparece como una de las primeras preocupaciones de lo que luego sería el profesor moderno, "el amigo de los niños", desde inicios del siglo XIX. De igual forma, el amor pedagógico, expresado en la pedagogía clásica de finales del siglo XIX, demandó el amor a la labor de enseñanza, así como también el desarrollo del niño en el proceso de aprendizaje.

Después, en la primera mitad del siglo XX, el amor fue asociado a lo que hacía el maestro, en el marco de la escuela activa, de manera que este, a la vez, debía ser de corazón joven, comprometido con el estudio, una persona disciplinada, quien igualmente debía promover la disciplina de la confianza como expresión de autonomía y madurez educativa en los estudiantes.

Por último, el amor al conocimiento y el amor a lo que enseña el maestro son consustanciales a lo que posteriormente sería el amor pedagógico, en la segunda mitad del siglo XX. Es decir, ese amor pedagógico puede ser visto como una práctica cargada 
de sentido, que se expresa en una relación de significado, y como una práctica simbólica, de carácter educativa, en la que no se puede romper el puente de comunicación que se establece entre el maestro y su discípulo, entre el profesor y el estudiante, entre el docente y la población.

Para concluir, el amor pedagógico ha pasado por tres momentos clave: el vocacional, el racional y el afectivo. Este último en la actualidad es indagado de manera sistemática, entre otros, por la investigadora argentina Ana Laura Abramowski ${ }^{7}$ (2006a), para quien el amor pedagógico, pensado desde los afectos, no es eterno, puro, natural, ni siempre bien intencionado, sino más bien hecho de sentimientos, placeres y emociones ambivalentes, cambiantes e historizables (p. 85). Para buena parte de este tipo de investigadores, la manera como el amor pedagógico en el mundo contemporáneo se ordena y funciona está mediada por una pedagogía afectizada (Dussel, 2006, p. 150), lo que nos permite muchas veces repensar de otra manera lo superfluo, lo momentáneo y lo banal del encuentro pedagógico dado entre los docentes y los estudiantes en el plano cotidiano.

Finalmente, la reflexión del amor pedagógico pensado en el plano afectivo y cotidiano de la escuela contemporánea demanda otro tipo de ejercicio académico situado y cualitativo, para el cual este artículo pretendió dejar algunas bases de reflexión conceptual. El amor pedagógico, como acontecimiento discursivo, se viene delimitando en el mundo contemporáneo como un enunciado, mediante el cual se puede problematizar no solo la formación y el compromiso, sino la práctica pedagógica del maestro en el plano cotidiano . $^{2}$ Así, el amor pedagógico liga el pasado con el presente; lo afectivo con lo emocional y experiencial; lo instituido y lo instituyente en la escuela; lo subjetivo con lo objetivo.

\section{Referencias}

Abramowski, A. (2006a). Un amor bien regulado. Los afectos magisteriales en la educación. En G. Frigeiro, \& G. Diker (Comps.), Educar: figuras y efectos del amor (pp. 81-99). El Estante.

Abramowski, A. (2006b). Maneras de querer. Los afectos docentes en las relaciones pedagógicas. Paidós.

Caldas de, F. (1941). Estudios varios. Imprenta Nacional; Biblioteca del Maestro en Ecuador.

Carvajal, C., \& Mesa, J. (1990). Historia de la Escuela Normal Central de Institutores y el Instituto Técnico Central. Universidad La Salle.

Dussel, I. (2006). Del amor y la pedagogía. Notas sobre las dificultades de un vínculo. En G. Frigeiro, \& G. Diker (Comps.), Educar: figuras y efectos del amor (pp. 145-158). El Estante.

Elias, N. (1975). Sociología fundamental. Gedisa

Fayad, J. (2010). Adquirir el don de la pedagogía significa defender la profesión docente.

7 Además del artículo citado (2006a), Abramowski en el mismo año dio a conocer un libro en el que desarrolla su hipótesis sobre amor pedagógico en la escuela: Maneras de querer. Los afectos docentes en las relaciones pedagógicas (2006b).

8 Esta es la mirada de Neira (2020) en su proyecto de tesis Maneras de decir el amor pedagógico en maestros de colegios públicos. Prácticas y discursos, Bogotá 2002-2020, del Doctorado Interinstitucional en Educación, sede Universidad Distrital Francisco José de Caldas. 
En A. Martínez, \& A. Álvarez (Comps.), Figuras contemporáneas del maestro en América Latina (pp. 229-258). Magisterio.

Ginzburg, C. (2004). Tentativas. Protohistoria Ediciones.

Herbart, J. (1914). Pedagogía general derivada del fin de la educación. Ediciones de La Lectura.

Jiménez, A. (2004). Algunos elementos para la investigación en la historia. En A. Jiménez, \& A. Torres (Comps.), La práctica investigativa en ciencias sociales (pp. 133-150). UPN.

Jiménez. A. (2018). Historia del pensamiento pedagógico colombiano. Universidad Distrital Francisco José de Caldas; CIDC.

Jiménez A. (2021). Cuatro ensayos sobre Michel Foucault: una mirada metodológica y conceptual para pensar la historia de la educación. Universidad Distrital Francisco José de Caldas DIE.

Luzuriaga, L. (1961). Historia de la educación y la pedagogía. Losada.

Neira, Á. (2020). Maneras de decir el amor pedagógico en maestros de colegios públicos. Prácticas y discursos, Bogotá 2002-2020 [Tesis Doctoral no publicada]. Universidad Distrital Francisco José de Caldas.

Nieto, A. (1966). Una escuela. Antares; Tercer Mundo Editores.

Pestalozzi, J. (1996). Canto del cisne. Porrúa.

Platón. (1997). El banquete. Alianza.

Restrepo, L., \& Restrepo, M. (1911). Elementos de pedagogía. Obra adoptada como texto para las escuelas normales de Colombia y recomendada para la enseñanza de la materia en el Ecuador (4 $4^{\mathrm{a}}$ ed.). Imprenta Moderna.

Restrepo, M. (1912). Pedagogía doméstica. Autoeducación, dirección del hogar y educación de los hijos. Arboleda y Valencia.

Rousseau, J. (2004). Emilio o de la educación. Porrúa.

Saldarriaga, Ó. (2003). Del oficio de maestro. Prácticas y teorías de la pedagogía moderna en Colombia. Magisterio.

Saldarriaga, Ó. (2006). Del amor pedagógico y otros demonios. En G. Frigeiro, \& G. Diker, (Comps.), Educar: figuras y efectos del amor (pp. 45-62). El Estante.

Suárez, H., \& Valencia, E. (Comps.). (1995). Educación y democracia: un campo de combate. Fundación Estanislao Zuleta; Corporación Tercer Milenio.

Zuleta, E. (1982). Sobre la lectura. http://www.ram-wan.net/restrepo/metodologia/zuleta sobre\%20la\%20lectura.pdf

Zuleta, E. (1975). Teoría Freudiana de la infancia. En Centro Psicoanalítico Sigmund Freud (Ed.), Documentos patrimoniales (pp.32-57). Biblioteca Universidad de Antioquia.

Zuluaga. O. (2018). La instrucción pública en Colombia, 1845-1868. Universidad de Antioquia; Aula Editorial. 